\title{
Genetics of osteoporotic fracture
}

This article was published in the following Dove Press journal:

Orthopedic Research and Reviews

I4 March 20I I

Number of times this article has been viewed

\author{
Chuan Qiu ${ }^{1,2}$ \\ Christopher J Papasian² \\ Hong-Wen Deng ${ }^{1,2,3,4}$ \\ Hui Shen ${ }^{1,2}$ \\ 'Center for Bioinformatics \\ and Genomics, Department of \\ Biostatistics and Bioinformatics, \\ School of Public Health and Tropical \\ Medicine, Tulane University, New \\ Orleans, Louisiana, USA; ${ }^{2}$ Department \\ of Basic Medical Sciences, School of \\ Medicine, University of Missouri- \\ Kansas City, Kansas City, Missouri, \\ USA; ${ }^{3}$ Center of System Biomedical \\ Sciences, University of Shanghai for \\ Science and Technology, Shanghai, \\ China; ${ }^{4}$ Molecular and Statistical \\ Genetics Lab, College of Life Sciences, \\ Hunan Normal University, Changsha, \\ China
}

Correspondence: Hui Shen

Center for Bioinformatics and Genomics, Department of Biostatistics and Bioinformatics, School of Public Health and Tropical Medicine, Tulane

University, I 440 Canal Street,

Ste 200I, New Orleans, LA 70I I2, USA

$\mathrm{Tel}+\mathrm{I} 5049886987$

Fax + I 5049881706

Email hshen3@tulane.edu

\begin{abstract}
Osteoporosis is a major public health problem that results in a massive burden to patients and society through associated low-trauma, osteoporotic fractures. Previous studies have shown that osteoporosis-associated traits, such as low bone mineral density, as well as the probability of actually experiencing an osteoporotic fracture, are under strong genetic control. Susceptibility to osteoporosis and osteoporotic fractures is likely to be controlled by multiple genetic and environmental factors, and by interactions between them. Although numerous genetic studies, mainly candidate gene association studies, have attempted to decipher the genetic basis for osteoporosis and osteoporotic fractures, little success has been achieved. Recent advances in high-throughput genotyping technology and knowledge of common human genetic variants have shifted the approach for studying human complex disorders from candidate gene studies to large-scale genome-wide association studies. In the past three years, more than 10 genome-wide association studies have been carried out for osteoporosis. A number of genes that are associated with osteoporosis-related traits, and/or with the probability of actually experiencing an osteoporotic fracture, have been successfully identified and replicated through these studies. In this article, we review the recent progress in the genetics of osteoporosis, with an emphasis on studies that have focused on genes that directly affect osteoporotic fractures.
\end{abstract}

Keywords: osteoporotic fracture, candidate gene association study, genome-wide association study

\section{Introduction}

Osteoporosis, characterized by low bone mass with microarchitectural deterioration and skeletal fragility, is the most prevalent metabolic bone disease in the elderly. Individuals with osteoporosis are at increased risk for low-trauma osteoporotic fractures, particularly at the spine, hip, and wrist. ${ }^{1}$

It is currently estimated that approximately 12 million people over the age of 50 years in the US have osteoporosis, and an additional 30-40 million people are at risk for osteoporotic fractures. ${ }^{2}$ The lifetime risk of suffering an osteoporotic fracture is estimated to be approximately $50 \%$ in women and about $20 \%$ in men., Osteoporotic fractures are associated with excessive morbidity and mortality., ${ }^{5,6}$ In fact, over $20 \%$ of patients who suffer a hip fracture die within one year of their injury, and half of those who do survive can no longer live independently. The economic burden caused by osteoporotic fractures is substantial, with an estimated annual direct care expenditure of \$19 billion in the US, ${ }^{7}$ and it is estimated that indirect costs (eg, lost productivity for patients and caregivers) add billions of dollars to this figure. Due primarily to the aging population, it is anticipated 
that the number of osteoporotic fractures and associated costs could double or even triple in the coming decades. ${ }^{7}$

Multiple studies, ${ }^{8-10}$ including a recent World Health Organisation meta-analysis of 60,000 individuals, ${ }^{11}$ have suggested that a parental history of fracture is a major risk factor for osteoporotic fractures. Genetic epidemiological studies have provided direct evidence supporting the concept that susceptibility to osteoporotic fractures is under genetic control, ${ }^{12-14}$ with estimated heritability ranging from 0.2 to $0.68 .^{15,16}$ Interestingly, although low bone mineral density is a major risk factor for osteoporotic fractures ${ }^{17}$ and bone mineral density has been used as the predominant surrogate phenotype for osteoporotic fractures in genetic studies, ${ }^{18,19}$ the genetic correlation between bone density and osteoporotic fractures is actually very low. This suggests that the genetic factors influencing bone density and osteoporotic fractures are largely independent of one another. ${ }^{15,20}$ It is therefore critical to conduct genetic studies for osteoporotic fractures directly, rather than relying predominantly upon surrogate indicators, such as bone density. Furthermore, all genes that are found to be important for bone density or other risk factors for osteoporotic fractures should be tested for their direct relevance to these fractures. ${ }^{21}$

In the past three years, a number of genetic factors contributing to risk of osteoporotic fractures have been identified, mainly through genome-wide association studies. In this article, we review recent progress in human genetic studies of osteoporotic fractures, and discuss future directions that can be used to search for genetic factors underlying osteoporotic fractures.

\section{Candidate gene association studies}

As with all other complex disorders, early genetic studies of osteoporotic fractures relied heavily on candidate gene association approaches, and results were largely inconsistent across different studies. ${ }^{18}$ The lack of reproducibility of early candidate gene association studies is not unique to osteoporosis; this is a common phenomenon in the field of genetics of human complex disorders. As we have discussed previously, ${ }^{22}$ one of the main reasons for this lack of reproducibility is overinterpretation of nominally significant results from studies with insufficient statistical power. More recently, large collaborative studies with adequate sample size have begun to provide a clearer delineation of the association between osteoporotic fractures and a number of candidate genes. ${ }^{23} \mathrm{~A}$ few specific candidate genes are discussed below, and a more comprehensive list can be found in several excellent review articles. ${ }^{18,23,24}$

\section{Vitamin $D$ receptor gene}

The $V D R$ gene is one of the most extensively studied candidate genes for osteoporotic fractures. The largest study of the $V D R$ gene reported to date was performed by the Genetic Markers for Osteoporosis (GENOMOS) consortium, which included 6067 fracture patients (2088 had vertebral fractures) and 20,175 controls. ${ }^{25}$ In this study, no significant association was detected between osteoporotic fractures and four "classical" VDR polymorphisms, namely, FokI, BsmI, ApaI, and TaqI. However, the $\mathrm{Cdx} 2$ polymorphism showed a modest association $(P=0.039)$ with risk for vertebral fractures. ${ }^{25}$ Grundberg et $\mathrm{al}^{26}$ studied the association between common haplotypes defined by the BsmI, ApaI, and TaqI polymorphisms and risk of vertebral fractures in elderly men from Sweden ( $n=3014$, including 208 vertebral fractures). The baT haplotype was found to be associated with increased risk of vertebral fractures (odds ratio $[\mathrm{OR}]=1.65,95 \%$ confidence interval $[\mathrm{CI}]: 1.146-2.391, P<0.01)$, independent of body weight, height, age, and bone density. More recently, a literature-based meta-analysis of 17 studies generated a combined sample of 2112 fracture cases and 4521 controls to test for associations between osteoporotic fractures and FokI, BsmI, ApaI, and TaqI polymorphisms of the VDR gene. ${ }^{27}$ When stratifying by fracture type, they found that hip fracture cases had a significantly lower frequency of the bb genotype for BsmI (OR $=0.82,95 \% \mathrm{CI}: 0.70-0.97)$ and the $\mathrm{Tt}$ genotype for TaqI (OR $=0.65,95 \% \mathrm{CI}: 0.43-0.97)$, but a significantly higher frequency of the tt genotype for TaqI (OR = 1.74, 95\% CI: 1.05-2.91). Additionally, subjects with the Aa genotype of ApaI had a significantly higher risk of vertebral fracture $(\mathrm{OR}=1.63,95 \% \mathrm{CI}: 1.03-2.59){ }^{27}$ Together, these studies suggested that there is a modest, but statistically significant, association between specific VDR polymorphisms and osteoporotic fractures.

\section{Type I collagen $\alpha$ I gene}

The COL1A1 gene encodes the alpha 1 chain of type I collagen, which is the most abundant structural protein in the bone matrix. Mutations in the COL1A1 gene can cause osteogenesis imperfecta, a Mendelian disorder presenting with moderate to severe bone fragility. ${ }^{28-30}$ The COL1A1 gene has been extensively studied in relation to bone mineral density and osteoporotic fractures. ${ }^{18,19}$ The majority of these studies have focused on the G/T polymorphism located in intron 1 of the COL1A1 gene, which affects a binding site for transcription factor $\mathrm{Sp} 1 .^{31}$ The GENOMOS consortium performed a prospective participant-level meta-analysis for the COL1A1 Sp1 polymorphism in relation to fractures in 20,786 unrelated 
Caucasian subjects, including 6067 individuals with any fracture, 2088 with vertebral fractures, and 2407 with incident fractures (412 had incident vertebral fractures). ${ }^{32}$ Although the COL1A1 Sp1 polymorphism was not associated with overall fractures, there was a nonsignificant trend toward association with vertebral fracture, and a nominally significant association with incident vertebral fractures in females $(\mathrm{OR}=1.33$, 95\% CI: 1.00-1.77, $P=0.05$ ). Further adjustment for lumbar spine bone density and postmenopausal status did not considerably alter any of these effects. ${ }^{32}$ Similar to what had been conducted for $V D R$ polymorphisms, a literature-based meta-analysis was also recently published for the COL1A1 Sp1 polymorphism, involving 2294 patients with fractures and 10,285 controls. ${ }^{33}$ In contrast with the results from the GENOMOS study, a significant difference in genotype distribution was detected between overall patients with fractures and controls. ${ }^{33}$ Further analyses suggested that the SS genotype is associated with reduced risk for both vertebral $(\mathrm{OR}=0.58,95 \% \mathrm{CI}: 0.38-0.90)$ and nonvertebral $(\mathrm{OR}=0.80$, 95\% CI: 0.68-0.95) fractures. ${ }^{33}$ These studies suggest that the COLIA1 Sp1 polymorphism may confer very modest effects on the susceptibility to osteoporotic fractures.

The value of candidate gene studies, such as those reviewed above, is inherently limited due to their focus on a few specific candidate genes, the biological function of which is known to be related to bone development and metabolism; this approach precludes the identification of novel osteoporotic fracture susceptibility genes. In addition, these studies normally test only a few previously typed polymorphisms, and thus cannot determine whether other variants in the selected candidate genes may contribute to the susceptibility of osteoporotic fractures. Furthermore, most, if not all, of these studies are not properly controlled for population stratification, because they do not have ancestry informative marker data available. For these reasons, results of candidate gene studies, even large collaborative studies, such as GENOMOS, ${ }^{22,32,34,35}$ must be interpreted with caution. ${ }^{36}$

\section{Genome-wide association studies}

Analogous to other polygenic complex diseases, susceptibility to osteoporotic fractures is likely to be influenced by multiple genes, each with small to modest effects. Therefore, it is critical to perform unbiased, hypothesis-free searches across the entire human genome to identify genetic factors underlying osteoporotic fractures. Recent advances in high-throughput single nucleotide polymorphism genotyping technology, and knowledge of common genetic variants in the human genome, ${ }^{37,38}$ have made large-scale genome-wide association studies (GWAS) feasible. Study populations for GWAS often include thousands of individuals, and each individual is typically evaluated for hundreds of thousands to millions of single nucleotide polymorphisms distributed throughout the entire genome. In the past three years, more than 10 GWAS of osteoporosis have been performed, mainly focused on bone mineral density variation rather than osteoporotic fractures per se. In this section, we review GWAS that have identified susceptibility genes of osteoporotic fractures.

\section{deCODE Genetics}

By genotyping approximately 300,000 single nucleotide polymorphisms in 5861 Icelandic subjects, deCODE Genetics conducted the first large and comprehensive GWAS of bone mineral density. ${ }^{39}$ Five genomic regions, encompassing the major histocompatibility complex region and the RANKL, OPG, ESR1, and ZBTB40 genes, attained genome-wide significant associations with bone mineral density. ${ }^{39}$ Twelve of the most significant single nucleotide polymorphisms in these five regions, along with eight other single nucleotide polymorphisms showing suggestive associations with bone mineral density, were tested for associations with low-trauma fracture using 4406 fracture cases collected from Iceland, Australia, and Denmark. ${ }^{39-42}$ Significant associations were detected for the $Z B T B 40$ gene $\left(P=0.016-2.4 \times 10^{-4}\right)$ and for the major histocompatibility complex region $(P=0.044-0.008)$ with osteoporotic fractures at specific skeletal sites (hip, forearm, and vertebral) and with broadly defined osteoporotic fractures. ${ }^{39}$ The $O P G$ gene showed a nominally significant association $(P=0.04)$ with broadly defined osteoporotic fractures, and no association with osteoporotic fractures was detected for the ESRI or RANKL genes. ${ }^{39}$ Interestingly, several genes that did not attain genome-wide significant associations with bone mineral density showed evidence of an association with osteoporotic fractures. These included the $R A N K$ gene $(P=0.005)$, the SPTBN1 gene $\left(P=1.8 \times 10^{-4}\right)$, and the LRP4 gene $(P=0.007) .{ }^{39}$ For all of these loci, the effects on osteoporotic fractures were rather modest, with OR ranging from 1.06 to $1.15 .^{39}$ Following the initial GWAS, the deCODE Genetics group expanded their discovery and replication cohorts, and re-evaluated 100 single nucleotide polymorphisms and 20 nonsynonymous or potentially functional single nucleotide polymorphisms that produced the most significant associations in their initial GWAS. ${ }^{43}$ Four new loci attained genome-wide significant associations with bone mineral density, including the SOST gene, the SP7 
gene, the MARK3 gene, and the RANK gene. ${ }^{43}$ Notably, single nucleotide polymorphisms in the SOST gene and the MARK3 gene also had modest effects on low-trauma fractures $(\mathrm{OR}=1.07-1.10){ }^{43}$

\section{TwinsUK and Rotterdam}

In this study of 2094 women from the TwinsUK cohort and 4081 unrelated Dutch subjects from the Rotterdam study, 314,075 single nucleotide polymorphisms were evaluated for association with bone mineral density. ${ }^{44}$ The results were replicated in two independent cohorts. One single nucleotide polymorphism near the $O P G$ gene, and one nonsynonymous single nucleotide polymorphism (rs3736228) in the LRP5 gene, showed genome-wide significant associations with bone density variation. ${ }^{44}$ The risk allele at rs 3736228 was also associated with an increased risk of osteoporotic fractures $(\mathrm{OR}=1.3,95 \% \mathrm{CI}: 1.09-1.52, P=0.002)$. This association persisted after adjustment for bone mineral density $(\mathrm{OR}=1.22,95 \% \mathrm{CI}: 1.02-1.45, P=0.03),{ }^{44}$ suggesting that this locus may influence the risk of osteoporotic fractures, independent of its effects on bone mineral density.

\section{Chinese and US Midwest}

By using a cohort of 700 elderly Chinese Han subjects (350 hip osteoporotic fracture cases and 350 healthy matched controls), our group performed the first GWAS specifically focused on hip osteoporotic fractures. ${ }^{45}$ Major findings in this GWAS were further validated in an independent replication cohort, containing 390 hip osteoporotic fracture patients and 516 matched controls. ${ }^{45}$ Both the GWAS discovery cohort and the replication cohorts were collected from the area of Xi'an, China. Stringent inclusion/exclusion criteria were applied for recruitment of both cases and controls, and all hip fractures were identified or confirmed through diagnosis by orthopedic surgeons or radiologists with radiological evidence. ${ }^{45} \mathrm{We}$ found that one single nucleotide polymorphism, rs13182402, within the ALDH7A1 gene, was strongly associated with hip osteoporotic fractures in both the discovery $\left(P=8.53 \times 10^{-9}\right)$ and replication cohorts $(\mathrm{OR}=2.25$, 95\% CI: 1.72-2.94, combined $\left.P=2.08 \times 10^{-9}\right) .{ }^{45}$ This single nucleotide polymorphism also showed a modest association with hip bone density (combined $P=6.39 \times 10^{-6}$ ) in additional Chinese and Caucasian samples $(\mathrm{n}=9962) .{ }^{45}$ Unfortunately, bone mineral density measurements were not available for the hip osteoporotic fracture cases, so we could not determine whether the effect of this single nucleotide polymorphism on risk of hip osteoporotic fractures was through its influence on bone density or independent of this effect. ${ }^{45}$
Copy number variation refers to a segment of DNA that is present in varying copy numbers in genomes of different individuals. Copy number variations can influence gene expression, and have been implicated in the etiology of several human complex diseases. ${ }^{46-48}$ Using the same Xi'an hip osteoporotic fracture cohort, we constructed a genomewide copy number variation map containing 727 copy number variation regions in Chinese individuals, and detected a strong association between a copy number variation on chromosome 4q13.2 and hip osteoporotic fractures $(\mathrm{OR}=1.73$, 95\% CI: $\left.1.22-2.45, P=2.0 \times 10^{-4}\right) .{ }^{49}$ Subsequent molecular analyses fine-mapped the copy number variation to a $150 \mathrm{~kb}$ interval spanning the $U G T 2 B 17$ gene. ${ }^{49}$ Furthermore, the association between $U G T 2 B 17$ copy number variations with hip osteoporotic fractures was successfully replicated in the independent hip osteoporotic fractures cohort $\left(P=6.34 \times 10^{-3}\right){ }^{49}$ This copy number variation also showed modest associations with hip bone mineral density and femoral neck bone geometry $\left(P=5.0 \times 10^{-4}-0.021\right)$ in additional independent Chinese and Caucasian samples. ${ }^{49}$ Because the UGT2B17 gene encodes an enzyme catabolizing steroid hormones, we also tested the association between this copy number variation and the serum concentrations of testosterone and estradiol. Compared with subjects having one or two copies of $U G T 2 B 17$, subjects with no copies of this gene had significantly higher serum concentrations of testosterone $(P=0.005)$ and estradiol $(P=0.01) .{ }^{49}$ Taken together, our results suggested a putative mechanism for osteoporotic fracture by which the UGT2B17 gene inhibits steroid hormone levels, thereby compromising bone mass and integrity and increasing the risk of osteoporotic fractures. ${ }^{49}$

To identify additional osteoporosis susceptibility genes, we performed GWAS for bone mineral density ${ }^{50}$ and other osteoporosis-related traits (eg, bone size $)^{51}$ in 1000 unrelated Caucasians, recruited from the US Midwest. We observed significant associations between the ADAMTS18 gene and hip bone mineral density ${ }^{50}$ and between the PLCL1 gene and bone size. ${ }^{51}$ In addition, both the ADAMTS18 and the PLCL1 genes showed modest associations with hip osteoporotic fractures $\left(P=7.66 \times 10^{-3}-0.019\right) .{ }^{50,51}$ Supporting this finding, a recent study suggested that the PLCL1 gene may also confer modest effects on the risk of vertebral fracture in postmenopausal Danish women. ${ }^{52}$

\section{Genetic factors for osteoporosis}

Representing a commendable collaborative effort that included 19,195 subjects of Northern European descent, the GEFOS consortium combined five GWAS to perform 
a large-scale meta-analysis of bone mineral density. ${ }^{53}$ Twenty genomic loci showed strong associations with bone density, and these loci included 13 genes that had not previously been significantly associated with bone density at the genome-wide level..$^{53}$ After combining the effects of the top 20 bone density loci, the association between the compound allelic scores and the risk of fracture was assessed in 2727 radiographically screened individuals (302 vertebral fracture cases) and in 4865 individuals followed for an average of 8.2 years (672 nonvertebral fractures) ${ }^{53}$ Despite limited power, a significant association was observed between the compound femoral neck bone density allelic score and the risk of incident nonvertebral fracture (hazards ratio $[\mathrm{HR}]=1.042$, 95\% CI: $1.003-1.084, P=0.04) .{ }^{53}$ Similarly, the compound lumbar spine bone density allelic score was significantly associated with the risk of vertebral fracture $(\mathrm{OR}=1.061,95 \%$ CI: $1.009-1.116, P=0.02) .{ }^{53}$ Adjustment for bone mineral density showed that approximately $25 \%-50 \%$ of the genetic effect on fracture could not be explained by bone density. ${ }^{53}$

Using the same GWAS meta-analysis data, the GEFOS consortium also evaluated 36,015 single nucleotide polymorphisms surrounding 150 osteoporosis candidate genes to determine whether they were associated with either bone density or fracture (900 nonvertebral osteoporotic fracture patients and 329 vertebral osteoporotic fracture patients). ${ }^{54}$ Single nucleotide polymorphisms from nine candidate genes were significantly associated with bone mineral density. Of these, single nucleotide polymorphisms from five candidate genes, specifically $L R P 5, S O S T, S P P 1, R A N K L$, and $R A N K$, were also significantly associated with osteoporotic fractures, with an estimated OR ranging from 1.13 to $1.43 .{ }^{54}$ After accounting for their association with bone mineral density, single nucleotide polymorphisms from the SOST and the $L R P 5$ genes retained statistically significant associations with nonvertebral osteoporotic fractures, and single nucleotide polymorphisms from the SPP1 gene showed persistent associations with vertebral osteoporotic fractures. ${ }^{54}$ These results suggest that some of these genes may have effects on the risk of osteoporotic fractures that are not mediated through bone mineral density, but perhaps through their effects on other aspects of bone strength or nonskeletal factors, such as the propensity to fall. ${ }^{55}$

\section{Hong Kong Southern Chinese}

Recently, Kung et al carried out a GWAS for bone mineral density using a discovery cohort of 800 unrelated Hong Kong Southern Chinese females with extreme bone density values (bottom $10 \%$ or top $16 \%$ of the population) and performed a two-phase replication study in six independent populations that included 18,098 subjects. ${ }^{56}$ They identified and replicated a novel association between bone mineral density variation and single nucleotide polymorphism rs2273601 of the $J A G 1$ gene. ${ }^{56}$ In a sample of 244 osteoporotic fracture cases and 1637 controls, they found that this $J A G 1$ single nucleotide polymorphism was also associated with the risk of osteoporotic fractures $(P=0.009$, OR $=0.7,95 \%$ CI: $0.57-0.93, \mathrm{n}=1881)$, and that this association was partly, but not completely, attenuated if bone mineral density was added as a covariate in the analysis $(P=0.031, \mathrm{OR}=0.8,95 \% \mathrm{CI}$ : $0.58-0.97){ }^{56}$ Therefore, the $J A G 1$ gene may exert its effects on the risk of osteoporotic fractures through mechanisms that are both dependent and independent of bone density.

\section{Perspectives}

GWAS have dramatically advanced our ability to identify osteoporosis susceptibility genes. To date, associations with bone density variation and/or risk of osteoporotic fractures have been identified and replicated for more than 40 genes or genomic regions by GWAS (Table 1). These implicated genes/regions have included genes in known major bone biology pathways, such as the RANK/RANKL/ $O P G$ and $W n t / L R P 5$ pathways, as well as a number of novel osteoporosis susceptibility genes. Interestingly, these genes are enriched in three major networks (Figure 1), suggesting that they may act interactively to affect the predisposition of osteoporosis. The findings of GWAS have provided new insights into the complex genetic and molecular mechanisms underlying osteoporosis. Importantly, several genes have shown significant associations with osteoporotic fractures, independent of their effects on bone mineral density. Although this result was not unexpected based on the low level of genetic correlation between bone mineral density and osteoporotic fractures, it further highlights the importance of directly targeting the osteoporotic fracture phenotype for genetic studies of osteoporosis.

Despite the tremendous benefits of utilizing GWAS, it is important to recognize that current GWAS are constrained by a number of limitations. For instance, current GWAS only focus on common variants in the human genome, mainly single nucleotide polymorphisms, and the collective effects of the loci identified to date explain less than 5\% of the estimated heritability of bone mineral density and an even smaller fraction of the heritability for osteoporotic fractures.$^{56}$ Hence, the vast majority of the heritable component of osteoporosis remains to be discovered. As with other complex traits (eg, height) ${ }^{57}$ it is likely that many additional 
Table I Osteoporosis susceptibility genes identified by genome-wide association studies

\begin{tabular}{|c|c|c|c|}
\hline Gene symbol & Gene description & Associated trait & References \\
\hline \multirow[t]{2}{*}{ ADAMTSI8 } & ADAM metallopeptidase with & Hip BMD & Xiong et $\mathrm{a}^{50}$ \\
\hline & thrombospondin type I motif, 18 & Hip osteoporotic fractures & \\
\hline \multirow[t]{2}{*}{ ALDH7AI } & Aldehyde dehydrogenase 7 family, & Hip BMD & Guo et $\mathrm{al}^{45}$ \\
\hline & member Al & Hip osteoporotic fractures & \\
\hline ARHGAPI & Rho GTPase activating protein I & Hip BMD & Rivadebeira et al ${ }^{53}$ \\
\hline CI7orf53 & Chromosome 17 open reading frame 53 & Hip/LS BMD & Styrkarsdottir et al ${ }^{43}$ \\
\hline \multirow[t]{2}{*}{ C6orf97 } & Chromosome 6 open & Hip/LS BMD & Styrkarsdottir et a ${ }^{39}$ \\
\hline & reading frame 97 & & Styrkarsdottir et a ${ }^{43}$ \\
\hline C6orflo & Chromosome 6 open reading frame 10 & Hip/LS BMD & Styrkarsdottir et a ${ }^{39}$ \\
\hline CNTNAP2 & Contactin associated protein-like 2 & Hip/LS BMD & Kiel et $\mathrm{a}^{74}$ \\
\hline CRHRI & Corticotropin releasing hormone receptor I & LS BMD & Rivadeneira et $\mathrm{al}^{53}$ \\
\hline CTNNBI & Catenin (cadherin-associated protein), beta I & Hip BMD & Rivadeneira et $\mathrm{a}^{53}$ \\
\hline CTNNBLI & Catenin, beta like I & Hip BMD & Kiel et $\mathrm{al}^{74}$ \\
\hline DCDC5 & Doublecortin domain containing 5 & LS BMD & Rivadeneira et $\mathrm{a}^{53}$ \\
\hline \multirow[t]{2}{*}{ ESRI } & Estrogen receptor I & Hip/LS BMD & Styrkarsdottir et a $\left.\right|^{43}$ \\
\hline & & osteoporotic fractures & Rivadeneira et al ${ }^{53}$ \\
\hline FLJ42280 & Hypothetical LOC40I388 & Hip/LS BMD & Rivadeneira et $\mathrm{a}^{53}$ \\
\hline FOXLI & Forkhead box LI & Hip/LS BMD & Rivadeneira et $\mathrm{a}^{53}$ \\
\hline GPRI77 & G protein-coupled receptor 177 & Hip/LS BMD & Rivadeneira et $a^{53}$ \\
\hline HDAC5 & Histone deacetylase 5 & Hip/LS BMD & Rivadeneira et $\mathrm{a}^{53}$ \\
\hline IL2IR & Interleukin 21 receptor & FN BMD & Guo et $\mathrm{al}^{75}$ \\
\hline JAGI & Jagged I & LS/FN BMD & Kung et $\mathrm{al}^{56}$ \\
\hline \multirow[t]{2}{*}{ LOC344382 } & Serine/threonine kinase receptor & Hip/LS BMD & Styrkarsdottir et al ${ }^{43}$ \\
\hline & associated protein pseudogene & & \\
\hline LRP4 & Low density lipoprotein receptor-related protein 4 & Hip BMD & Styrkarsdottir et a $\left.\right|^{43}$ \\
\hline \multirow[t]{2}{*}{ LRP5 } & Low density lipoprotein receptor-related protein 5 & Hip/LS BMD & Richards et $\mathrm{al}^{44}$; Rivadeneira et $\mathrm{a}^{53}$ \\
\hline & & & Richards et $\mathrm{al}^{54}$ \\
\hline MARK3 & MAP/microtubule affinity-regulating kinase 3 & Hip/LS BMD & Styrkarsdottir et al ${ }^{43}$ \\
\hline MEF2C & Myocyte enhancer factor $2 \mathrm{C}$ & Hip BMD & Rivadeneira et $\mathrm{a}^{53}$ \\
\hline MEPE & Matrix extracellular phosphoglycoprotein & Hip/LS BMD & Rivadeneira et $\mathrm{al}^{53}$ \\
\hline $\mathrm{MHC}$ & Major histocompatibility complex & Hip/LS BMD & Styrkarsdottir et a ${ }^{39}$ \\
\hline \multirow[t]{3}{*}{ OPG (TNFRSFIIB) } & Stimulation of Osteoprotegerin & Hip/LS BMD & The International HapMap \\
\hline & & & Project $^{38} ;$ Styrkarsdottir et $\mathrm{al}^{39}$ \\
\hline & & & Richards et $\mathrm{a}^{44}$; Rivadeneira et a $\mathrm{l}^{53}$ \\
\hline PTH & Parathyroid hormone & FN BMD & Guo et $\mathrm{al}^{75}$ \\
\hline \multirow[t]{2}{*}{ PLCLI } & Phospholipase C-like I & Hip BMD & Liu et $\mathrm{al}^{51}$ \\
\hline & & Hip osteoporotic fractures & \\
\hline \multirow[t]{3}{*}{ RANK (TNFRSFIIA) } & Receptor activator of nuclear factor $\kappa B$ & Hip/LS BMD & Styrkarsdottir et a ${ }^{39}$ \\
\hline & & & Styrkarsdottir et al ${ }^{43}$ \\
\hline & & & Rivadeneira et $\mathrm{a}^{53}$; Richards et $\mathrm{a}^{54}$ \\
\hline RANKL (TNFSFII) & Receptor activator of nuclear factor $\kappa B$ ligand & Hip/LS BMD & Rivadeneira et $\mathrm{a}^{53}$ \\
\hline \multirow[t]{2}{*}{ RBMS3 } & RNA binding motif, single stranded & Hip BMD & Kiel et $\mathrm{al}^{74}$ \\
\hline & interacting protein 3 & & \\
\hline \multirow[t]{2}{*}{ SOST } & Sclerostin & Hip BMD & Strykarsdottir et $\mathrm{al}^{39}$ \\
\hline & & & Styrkarsdottir et al ${ }^{43}$; Richards et a $\left.\right|^{54}$ \\
\hline \multirow[t]{2}{*}{ SPTBNI } & Spectrin, beta, non-erythrocytic I & LS BMD & Styrkarsdottir et al ${ }^{43}$ \\
\hline & & & Rivadeneira et al ${ }^{53}$ \\
\hline \multirow[t]{2}{*}{ SP7 } & Sp7 transcription factor & LS BMD & Styrkarsdottir et a $\left.\right|^{43}$ \\
\hline & & & Rivadeneira et al ${ }^{53}$ \\
\hline sox6 & Sex determining region Y-box 6 & Hip BMD & Rivadeneira et al ${ }^{53}$ \\
\hline \multirow[t]{2}{*}{ SPPI } & Secreted phosphoprotein I & Hip/LS BMD & Styrkarsdottir et a $\left.\right|^{43}$ \\
\hline & & LS osteoporotic fractures & Richards et $\mathrm{al}^{54}$ \\
\hline STARD3NL & STARD3 N-terminal like & LS BMD & Rivadeneira et $\mathrm{a}^{53}$ \\
\hline TGFBR3 & Transforming growth factor, beta receptor III & LS BMD & Xiong et $\mathrm{al}^{50}$ \\
\hline \multirow[t]{2}{*}{ UGT2BI7 } & UDP glucuronosyltransferase 2 family, & Hip BMD & Yang et al $\left.\right|^{49}$ \\
\hline & polypeptide BI7 & Hip osteoporotic fractures & \\
\hline \multirow[t]{2}{*}{ ZBTB40 } & zinc finger and BTB domain containing 40 & LS/FN BMD & Styrkarsdottir et a ${ }^{39}$ \\
\hline & & & Rivadeneira et al ${ }^{53}$ \\
\hline
\end{tabular}

Abbreviations: LS, lumbar spine; FN, femoral neck; BMD, bone mineral density. 

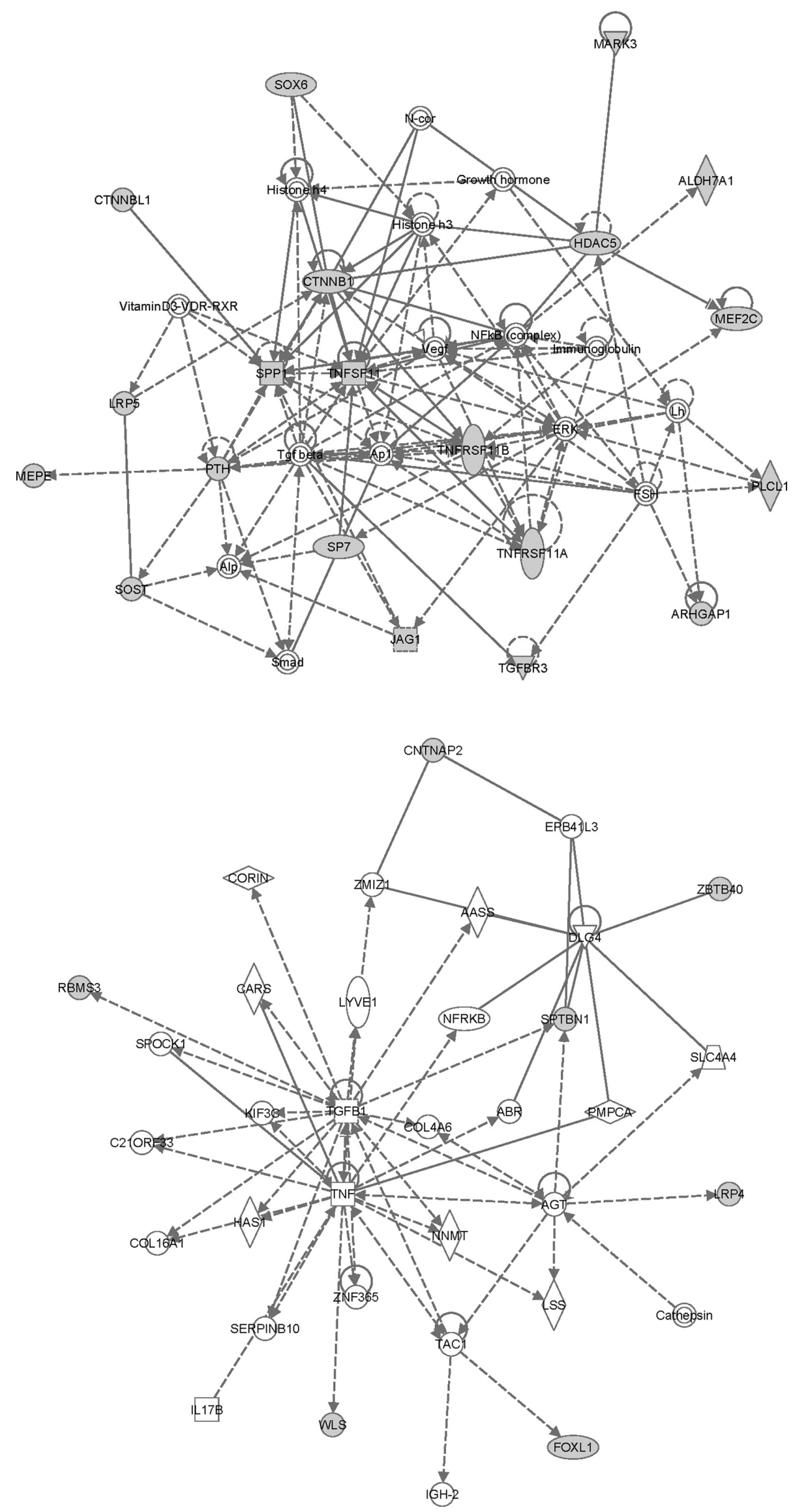

Figure I (Continued) 


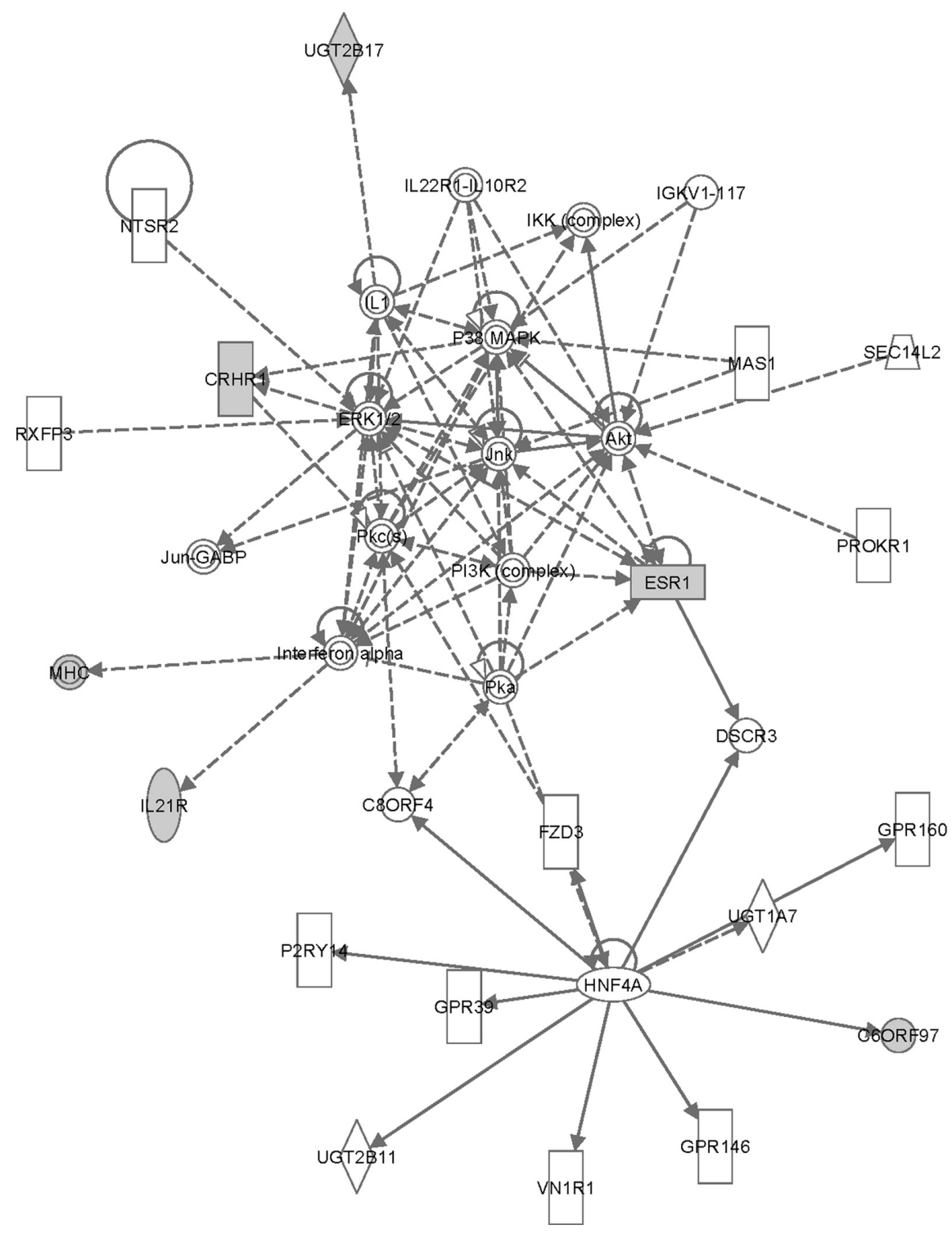

Figure I Three networks enriched for known osteoporosis susceptibility genes. The 40 known osteoporosis genes were evaluated for network analysis using Ingenuity Pathway Analysis software (Version 8.8, Ingenuity Systems Inc, Redwood City, CA). Three networks showed significant enrichment for osteoporosis susceptibility genes (highlighted in gray), including A) a network related to connective tissue development and function, skeletal and muscular system development and function, and tissue morphology, B) a network related to drug metabolism, lipid metabolism, and small molecule biochemistry, and C) a network related to lipid metabolism, small molecule biochemistry, and cellular response to therapeutics.

common variants with smaller effects, and a number of rare variants with larger effects on osteoporosis have, thus far, eluded identification. Moreover, it has also been suggested that gene-gene (epistasis) and gene-environment interactions may contribute significantly to the "missing" heritability of complex human diseases. ${ }^{58,59}$ However, genetic studies of humans rarely investigate these effects, partly because previous statistical methods for detecting these effects on a genome-wide scale are relatively poor. Fortunately, novel analytic approaches ${ }^{60-64}$ for genome-wide gene-gene and gene-environment interaction analyses are quickly emerging, and it is expected that implementation of these methods will lead to novel insights into the pathophysiology of osteoporotic fractures.

It is similarly important to exercise caution when carrying out GWAS meta-analyses for osteoporotic fractures. The current trend in genetics of osteoporosis is to perform larger and larger GWAS by pooling more and more individual studies into meta-analyses. Although such collaborative efforts are laudable and potentially important for the study of osteoporotic fractures, simply pooling samples together does not always improve statistical power. For instance, it is common to identify individuals with osteoporotic fractures through self-reporting and subsequent 
verification through review of medical records. However, the accuracy of this approach has been questioned. ${ }^{65,66}$ This is particularly true of vertebral osteoporotic fractures for which multiple identification methods have been proposed, and for which the agreement between these different methods is rather poor. ${ }^{67,68}$ Jiang et al compared three methods, namely, qualitative visual assessment, semiquantitative assessment, and an algorithm-based qualitative method, for identifying vertebral osteoporotic fractures. ${ }^{67}$ Of women with vertebral fractures identified by semiquantitative assessment, 53\% and $70 \%$ were categorized as negative for fracture by the algorithm-based qualitative method and qualitative visual assessment, respectively. ${ }^{67}$ The discrepancy is mainly due to difficulties in differentiating true fractures from nonfracture deformities or normal variants. In addition, osteoporotic fractures at different skeletal sites may have different underlying genetic mechanisms. Therefore, pooling vertebral osteoporotic fracture samples from studies which have used different ascertainment methods, or combining patients who had osteoporotic fractures at different skeletal sites (often referred to as broadly defined osteoporotic fractures), may dramatically increase phenotypic and/or genetic heterogeneity. This increased heterogeneity can in turn diminish rather than increase statistical power and generate false-negative and/or false-positive results. ${ }^{69,70}$ Furthermore, genotype imputation is commonly used for GWAS meta-analysis to accommodate differences in genotyping platforms used by different studies. However, inaccuracies in the imputed genotypes may also increase genetic heterogeneity, thereby increasing false-positive/ negative results (unpublished data). Due to these substantial limitations, current GWAS meta-analyses should not be considered a "gold standard" for determining whether a gene does or does not contribute to osteoporosis.

It is also essential to recognize that association does not imply causation. Indeed, none of the currently identified single nucleotide polymorphisms can be definitively designated as the actual causal or functional variant driving genetic associations. It is more likely that they are just "markers" that are in linkage disequilibrium with true functional variants that have not yet been identified. Refined deep-sequencing for the loci identified by GWAS, followed by cellular and molecular functional studies of selected variants, is required to identify and confirm the actual causal variants. Recent advances in next-generation sequencing technology ${ }^{71}$ combined with "systems genetics" or "systems biology" approaches, ${ }^{72,73}$ which apply sophisticated causality modeling and gene network analyses to integrate genomic, transcriptomic, proteomic, and metabolomic data, would represent powerful strategies for identifying and characterizing causal variants for osteoporotic fractures.

We expect continuous improvements in technology, study design, and statistical methods to greatly facilitate our ability to define the genetic architecture and mechanisms underlying osteoporosis. Furthermore, we expect the insights gained from these studies to be ultimately translated into improved methods for identifying individuals at risk for osteoporotic fractures, and new therapeutic interventions for preventing and treating these injuries.

\section{Acknowledgments}

The investigators were partially supported by grants from the National Institutes of Health and the Franklin D Dickson/ Missouri Endowment from the University of Missouri, Kansas City. The work was also partially supported by the Shanghai Leading Academic Discipline Project.

\section{Disclosure}

The authors report no conflicts of interest in this work.

\section{References}

1. Riggs BL, Melton LJ 3rd. The worldwide problem of osteoporosis: Insights afforded by epidemiology. Bone. 1995;17(5 Suppl):505S-511S.

2. Screening for osteoporosis: Recommendations from the US. Preventive Services Task Force. Ann Intern Med. January 17, 2011. [Epub ahead of print]

3. Holroyd C, Cooper C, Dennison E. Epidemiology of osteoporosis. Best Pract Res Clin Endocrinol Metab. 2008;22:671-685.

4. Cole ZA, Dennison EM, Cooper C. Osteoporosis epidemiology update. Curr Rheumatol Rep. 2008;10:92-96.

5. Harvey N, Dennison E, Cooper C. Osteoporosis: Impact on health and economics. Nat Rev Rheumatol. 2010;6:99-105.

6. Leboime A, Confavreux CB, Mehsen N, Paccou J, David C, Roux C. Osteoporosis and mortality. Joint Bone Spine. 2010;77 Suppl 2: S107-S112.

7. Burge R, Dawson-Hughes B, Solomon DH, Wong JB, King A, Tosteson A. Incidence and economic burden of osteoporosis-related fractures in the United States, 2005-2025. J Bone Miner Res. 2007;22:465-475.

8. Schnatz PF, Marakovits KA, O'Sullivan DM. Assessment of postmenopausal women and significant risk factors for osteoporosis. Obstet Gynecol Surv. 2010;65:591-596.

9. Grgurevic A, Gledovic Z, Vujasinovic-Stupar N. Factors associated with postmenopausal osteoporosis: A case-control study of Belgrade women. Women Health. 2010;50:475-490.

10. Papaioannou A, Kennedy CC, Cranney A, et al. Risk factors for low BMD in healthy men age 50 years or older: A systematic review. Osteoporos Int. 2009;20:507-518.

11. Kanis JA, Johnell O, Oden A, Johansson H, McCloskey E. FRAX and the assessment of fracture probability in men and women from the UK. Osteoporos Int. 2008;19:385-397.

12. Brot C, Jensen LB, Sorensen OH. Bone mass and risk factors for bone loss in perimenopausal Danish women. J Intern Med. 1997;242: 505-511.

13. Keen RW, Hart DJ, Arden NK, Doyle DV, Spector TD. Family history of appendicular fracture and risk of osteoporosis: A population-based study. Osteoporos Int. 1999;10:161-166. 
14. Siris ES, Miller PD, Barrett-Connor E, et al. Identification and fracture outcomes of undiagnosed low bone mineral density in postmenopausal women: Results from the National Osteoporosis Risk Assessment. JAMA. 2001;286:2815-2822.

15. Deng HW, Mahaney MC, Williams JT, et al. Relevance of the genes for bone mass variation to susceptibility to osteoporotic fractures and its implications to gene search for complex human diseases. Genet Epidemiol. 2002;22:12-25.

16. Michaelsson K, Melhus H, Ferm H, Ahlbom A, Pedersen NL. Genetic liability to fractures in the elderly. Arch Intern Med. 2005;165: $1825-1830$.

17. Cummings SR, Nevitt MC, Browner WS, et al. Risk factors for hip fracture in white women. Study of Osteoporotic Fractures Research Group. N Engl J Med. 1995;332:767-773.

18. Lei SF, Jiang H, Deng FY, Deng HW. Searching for genes underlying susceptibility to osteoporotic fracture: Current progress and future prospects. Osteoporos Int. 2007;18:1157-1175.

19. Xu XH, Dong SS, Guo Y, et al. Molecular genetic studies of gene identification for osteoporosis: The 2009 update. Endocr Rev. 2010;31: 447-505.

20. Andrew T, Antioniades L, Scurrah KJ, Macgregor AJ, Spector TD. Risk of wrist fracture in women is heritable and is influenced by genes that are largely independent of those influencing BMD. J Bone Miner Res. 2005;20:67-74.

21. Recker RR, Deng HW. Role of genetics in osteoporosis. Endocrine. 2002; 17:55-66.

22. Shen H, Liu Y, Liu P, Recker RR, Deng HW. Nonreplication in genetic studies of complex diseases - lessons learned from studies of osteoporosis and tentative remedies. J Bone Miner Res. 2005;20:365-376.

23. Cheung CL, Xiao SM, Kung AW. Genetic epidemiology of agerelated osteoporosis and its clinical applications. Nat Rev Rheumatol. 2010;6:507-517.

24. Ralston SH. Genetics of osteoporosis. Ann N Y Acad Sci. 2010;1192: 181-189.

25. Uitterlinden AG, Ralston SH, Brandi ML, et al. The association between common vitamin $\mathrm{D}$ receptor gene variations and osteoporosis: A participant-level meta-analysis. Ann Intern Med. 2006;145:255-264.

26. Grundberg E, Lau EM, Pastinen T, et al. Vitamin D receptor 3 ' haplotypes are unequally expressed in primary human bone cells and associated with increased fracture risk: The MrOS Study in Sweden and Hong Kong. J Bone Miner Res. 2007;22:832-840.

27. Ji GR, Yao M, Sun CY, Li ZH, Han Z. BsmI, TaqI, ApaI and FokI polymorphisms in the vitamin $\mathrm{D}$ receptor (VDR) gene and risk of fracture in Caucasians: A meta-analysis. Bone. 2010;47:681-686.

28. Byers PH. Brittle bones - fragile molecules: Disorders of collagen gene structure and expression. Trends Genet. 1990;6:293-300.

29. Dalgleish R. The human type I collagen mutation database. Nucleic Acids Res. 1997;25:181-187.

30. Rauch F, Glorieux FH. Osteogenesis imperfecta. Lancet. 2004;363: 1377-1385.

31. Grant SF, Reid DM, Blake G, Herd R, Fogelman I, Ralston SH. Reduced bone density and osteoporosis associated with a polymorphic Sp1 binding site in the collagen type I alpha 1 gene. Nat Genet. 1996;14: 203-205.

32. Ralston SH, Uitterlinden AG, Brandi ML, et al. Large-scale evidence for the effect of the COLIA1 Sp1 polymorphism on osteoporosis outcomes: The GENOMOS study. PLoS Med. 2006;3:e90.

33. Ji GR, Yao M, Sun CY, Zhang L, Han Z. Association of collagen type I alpha1 (COLIA1) Sp1 polymorphism with osteoporotic fracture in Caucasian post-menopausal women: A meta-analysis. J Int Med Res. 2009;37:1725-1732.

34. Van Meurs JB, Trikalinos TA, Ralston SH, et al. Large-scale analysis of association between LRP5 and LRP6 variants and osteoporosis. JAMA. 2008;299:1277-1290.

35. Loannidis JP, Ralston SH, Bennett ST, et al. Differential genetic effects of ESR1 gene polymorphisms on osteoporosis outcomes. JAMA. 2004; 292:2105-2114.
36. Brown MA. Genetic studies of osteoporosis - a rethink required. Calcif Tissue Int. 2005;76:319-325.

37. Frazer KA, Ballinger DG, Cox DR, et al. A second generation human haplotype map of over 3.1 million SNPs. Nature. 2007;449:851-861.

38. The International HapMap Project. Nature. 2003;426:789-796.

39. Styrkarsdottir U, Halldorsson BV, Gretarsdottir S, et al. Multiple genetic loci for bone mineral density and fractures. N Engl J Med. 2008; 358:2355-2365.

40. Tanko LB, Bagger YZ, Nielsen SB, Christiansen C. Does serum cholesterol contribute to vertebral bone loss in postmenopausal women? Bone. 2003;32:8-14.

41. Bagger YZ, Rasmussen HB, Alexandersen P, Werge T, Christiansen C, Tanko LB. Links between cardiovascular disease and osteoporosis in postmenopausal women: Serum lipids or atherosclerosis per se? Osteoporos Int. 2007;18:505-512.

42. Nguyen TV, Sambrook PN, Eisman JA. Sources of variability in bone mineral density measurements: Implications for study design and analysis of bone loss. J Bone Miner Res. 1997;12:124-135.

43. Styrkarsdottir U, Halldorsson BV, Gretarsdottir S, et al. New sequence variants associated with bone mineral density. Nat Genet. 2009;41: $15-17$.

44. Richards JB, Rivadeneira F, Inouye $\mathrm{M}$, et al. Bone mineral density, osteoporosis, and osteoporotic fractures: A genome-wide association study. Lancet. 2008;371:1505-1512.

45. Guo Y, Tan LJ, Lei SF, et al. Genome-wide association study identifies ALDH7A1 as a novel susceptibility gene for osteoporosis. PLoS Genet. 2010;6:e1000806.

46. Fanciulli M, Norsworthy PJ, Petretto E, et al. FCGR3B copy number variation is associated with susceptibility to systemic, but not organspecific, autoimmunity. Nat Genet. 2007;39:721-723.

47. Aitman TJ, Dong R, Vyse TJ, et al. Copy number polymorphism in Fcgr3 predisposes to glomerulonephritis in rats and humans. Nature. 2006;439:851-855.

48. Marshall CR, Noor A, Vincent JB, et al. Structural variation of chromosomes in autism spectrum disorder. Am J Hum Genet. 2008;82: $477-488$.

49. Yang TL, Chen XD, Guo Y, et al. Genome-wide copy-number-variation study identified a susceptibility gene, UGT2B17, for osteoporosis. Am J Hum Genet. 2008;83:663-674.

50. Xiong DH, Liu XG, Guo YF, et al. Genome-wide association and follow-up replication studies identified ADAMTS18 and TGFBR3 as bone mass candidate genes in different ethnic groups. Am J Hum Genet. 2009;84:388-398.

51. Liu YZ, Wilson SG, Wang L, et al. Identification of PLCL1 gene for hip bone size variation in females in a genome-wide association study. PLoS One. 2008;3:e3160.

52. Cauchi S, Byrjalsen I, Durand E, Karsdal MA, Froguel P. PLCL1 rs7595412 variation is not associated with hip bone size variation in postmenopausal Danish women. BMC Med Genet. 2009;10:145.

53. Rivadeneira F, Styrkarsdottir U, Estrada K, et al. Twenty bone-mineraldensity loci identified by large-scale meta-analysis of genome-wide association studies. Nat Genet. 2009;41:1199-1206.

54. Richards JB, Kavvoura FK, Rivadeneira F, et al. Collaborative metaanalysis: Associations of 150 candidate genes with osteoporosis and osteoporotic fracture. Ann Intern Med. 2009;151:528-537.

55. Wagner H, Melhus H, Pedersen NL, et al, Heritability of impaired balance: A nationwide cohort study in twins. Osteoporosis Int. 2009;20: 577-583.

56. Kung AW, Xiao SM, Cherny S, et al. Association of JAG1 with bone mineral density and osteoporotic fractures: A genome-wide association study and follow-up replication studies. Am J Hum Genet. 2010;86: 229-239.

57. Lango Allen H, Estrada K, Lettre G, et al. Hundreds of variants clustered in genomic loci and biological pathways affect human height. Nature. 2010;467:832-838.

58. Manolio TA, Collins FS, Cox NJ, et al. Finding the missing heritability of complex diseases. Nature. 2009;461:747-753. 
59. Eichler EE, Flint J, Gibson G, et al. Missing heritability and strategies for finding the underlying causes of complex disease. Nat Rev Genet. 2010;11:446-450.

60. Brinza D, Schultz M, Tesler G, Bafna V. RAPID detection of gene-gene interactions in genome-wide association studies. Bioinformatics. 2010; 26:2856-2862.

61. Zhang X, Huang S, Zou F, Wang W. TEAM: Efficient two-locus epistasis tests in human genome-wide association study. Bioinformatics. 2010;26:i217-i227.

62. Gauderman WJ, Thomas DC, Murcray CE, Conti D, Li D, Lewinger JP. Efficient genome-wide association testing of gene-environment interaction in case-parent trios. Am J Epidemiol. 2010;172:116-122.

63. Thomas D. Methods for investigating gene-environment interactions in candidate pathway and genome-wide association studies. Annu Rev Public Health. 2010;31:21-36.

64. Zhang X, Huang S, Zou F, Wang W. Tools for efficient epistasis detection in genome-wide association study. Source Code Biol Med. 2011;6:1.

65. Ismail AA, O'Neill TW, Cockerill W, et al. Validity of self-report of fractures: Results from a prospective study in men and women across Europe. EPOS Study Group. European Prospective Osteoporosis Study Group. Osteoporos Int. 2000;11:248-254.

66. Ivers RQ, Cumming RG, Mitchell P, Peduto AJ. The accuracy of selfreported fractures in older people. J Clin Epidemiol. 2002;55:452-457.
67. Jiang G, Eastell R, Barrington NA, Ferrar L. Comparison of methods for the visual identification of prevalent vertebral fracture in osteoporosis. Osteoporos Int. 2004;15:887-896.

68. Grados F, Fechtenbaum J, Flipon E, Kolta S, Roux C, Fardellone P. Radiographic methods for evaluating osteoporotic vertebral fractures. Joint Bone Spine. 2009;76:241-247.

69. Loannidis JP, Patsopoulos NA, Evangelou E. Heterogeneity in metaanalyses of genome-wide association investigations. PLoS One. 2007; 2:e841.

70. Lebrec JJ, Stijnen T, van Houwelingen HC. Dealing with heterogeneity between cohorts in genomewide SNP association studies. Stat Appl Genet Mol Biol. 2010;9:Article 8.

71. Metzker ML. Sequencing technologies - the next generation. Nat Rev Genet. 2010;11:31-46.

72. Farber CR, Lusis AJ. Future of osteoporosis genetics: Enhancing genomewide association studies. J Bone Miner Res. 2009;24:1937-1942.

73. Sharon D, Chen R, Snyder M. Systems biology approaches to disease marker discovery. Dis Markers. 2010;28:209-224.

74. Kiel DP, Demissie S, Dupuis J, Lunetta KL, Murabito JM, Karasik D. Genome-wide association with bone mass and geometry in the Framingham Heart Study. BMC Med Genet. 2007;8 Suppl 1:S14.

75. Guo Y, Zhang LS, Yang TL, et al. IL21R and PTH may underlie variation of femoral neck bone mineral density as revealed by a genomewide association study. J Bone Miner Res. 2010;25:1042-1048.
Orthopedic Research and Reviews

\section{Publish your work in this journal}

Orthopedic Research and Reviews is an international, peer-reviewed, open access journal focusing on the patho-physiology of the musculoskeletal system, trauma, surgery and other corrective interventions to restore mobility and function. Advances in new technologies, materials, techniques and pharmacological agents are particularly welcome. The journal welcomes

\section{Dovepress}

original research, clinical studies, reviews \& evaluations, expert opinion and commentary, case reports and extended reports. The manuscript management system is completely online and includes a very quick and fair peer-review system, which is all easy to use. Visit http://www.dovepress. com/testimonials.php to read real quotes from published authors. 